\title{
Relationship between Particle Size and Biological Activity of $E$. coli Boivin Endotoxin*
}

\author{
Hermann Beer, $\dagger$ Theophil Staehelin, Herndon Douglas, and \\ Abraham I. Braude + \\ (From the Department of Medicine, School of Medicine, University of Pittsburgh, \\ Pittsburgh, Pa.)
}

Many investigators have tried unsuccessfully to demonstrate that a specific chemical structure is responsible for the toxic action of bacterial endotoxins. Practically all of the protein (or peptide) and lipid constituents of the endotoxin molecule may be removed without affecting significantly its biological activities, and the carbohydrate moiety loses toxicity after it is depolymerized by even mild acid hydrolysis (1-4). Recent studies have also shown that toxicity does not depend upon the presence of the polysaccharide side chains that give the endotoxin its $\mathrm{O}$-antigenic specificity (5).

Other observations indicate that the size of the molecule, or molecular aggregate, is a more prominent determinant of toxicity than the chemical composition (6-7). Variations in particle size were noted by Schramm, Westphal, and Luderitz (8) in studies involving electron microscopy, sedimentation in the ultracentrifuge, and viscosity measurements. They demonstrated that endotoxins in solution are polydisperse, and the average particle weight was estimated at 24 million. The larger particles are formed by aggregation of identical subunits with a molecular weight of about 1 million.

The purpose of the present work was to get more quantitative information about the polydispersity of a Boivin endotoxin by sucrose density gradient centrifugation of endotoxin labeled uni-

* Submitted for publication August 5, 1964; accepted December 10, 1964.

Supported in part by U. S. Army medical contract no. DA-49-007-MD-872, grant H-3220 from the U. S. Public Health Service, and a grant from the Health Research and Services Foundation.

$\dagger$ Recipient of financial assistance from the University of Zurich.

¥ Address requests for reprints to: Dr. A. I. Braude, University of Pittsburgh School of Medicine, Pittsburgh, Pa. 15213. formly with $\mathrm{C}^{14}$ and to compare the biological activity in particles of different size. We found the highest lethal activity in those of an intermediate size, thus providing further evidence that size was a determinant of biological activity. When this concept was challenged, however, by dissociating the aggregates with sodium dodecyl sulfate (SDS) into smaller subunits, their toxic manifestations were unchanged. Particle size is thereby ruled out as a significant determinant of toxicity.

\section{Methods}

Reagents. Uniformly labeled glucose- $\mathrm{C}^{14}, \mathrm{Na}_{2} \mathrm{Cr}^{51} \mathrm{O}_{4}$ in sterile, pyrogen-free solution (Rachromate), ${ }^{2}$ pyrogenfree distilled water, ${ }^{2} 0.9 \% \mathrm{NaCl},{ }^{2} 5 \%$ glucose, ${ }^{2}$ and sodium dodecyl sulfate $(\mathrm{SDS}),{ }^{3}$ used without further purification, were obtained commercially.

Decontamination. Pyrogens were eliminated from equipment by heating at $170^{\circ} \mathrm{C}$ for at least 2 hours and from heat labile materials by immersing in $2 \frac{1}{2} \mathrm{~N} \mathrm{NaOH}$ for at least 2 hours. The $\mathrm{NaOH}$ was removed by rinsing with pyrogen-free distilled water. Sucrose gradients were prepared with pyrogen-free distilled water and sucrose solutions that were sterilized by Seitz filtration and shown to be free of pyrogens.

Preparation of endotoxins. Endotoxin was prepared by Boivin's method from a nonpiliated and nonflagellated strain of Escherichia coli $\mathrm{O}: 113$ that was originally isolated from the blood of a patient. It was stored as a frozen stock culture in trypticase soy broth, and smooth colonies were obtained on subculture for preparation of endotoxin in a synthetic medium containing glucose and $\mathrm{NH}_{4}{ }^{+}$as sole sources of carbon and nitrogen as previously described (9). It was labeled with $\mathrm{Na}_{2} \mathrm{Cr}^{51} \mathrm{O}_{4}$ according to a standard procedure in this laboratory (10). After dialysis against distilled water, the $\mathrm{Cr}^{51}$-labeled endotoxin was twice precipitated with ethanol to eliminate any free chromium.

Endotoxin was labeled biosynthetically with $\mathrm{C}^{14}$ by growing $E$. coli in $125 \mathrm{ml}$ of synthetic medium contain-

1 Nuclear-Chicago Corp., Des Plaines, Ill.

2 Abbott Laboratories, North Chicago, IIl

${ }^{3}$ Fisher Scientific Co., Fair Lawn, N. J. 
ing uniformly $\mathrm{C}^{14}$-labeled glucose instead of cold glucose. The labeled cells were mixed with a mass of unlabeled cells, and the endotoxin was prepared as usual. Since under these conditions all carbon atoms in the products of bacterial metabolism had statistically the same label, the amount of endotoxin in a sample could be calculated from the radioactivity.

In batch E-68-C $\mathrm{C}^{14}$ a total of $50 \mu \mathrm{c} \mathrm{C}^{14}$ of uniformly labeled glucose was used; in batch E-69-C ${ }^{14}, 150 \mu \mathrm{c}$. Specific activity of endotoxin E-68-C $C^{14}$ was $4,500 \mathrm{cpm}$ per $\mathrm{mg}$, and that of $\mathrm{E}-69-\mathrm{C}^{14}$ was $28,000 \mathrm{cpm}$ per $\mu \mathrm{g}$.

Antiserum. An immune serum was prepared in rabbits with cells of $E$. coli $\mathrm{O}: 113$ that had been boiled for $2 \frac{1}{2}$ hours. The animals were injected intravenously every other day for 3 weeks and bled 5 days after the last injection.

Sucrose density gradient. Linear sucrose gradients from $1.0 \mathrm{M}$ to $0.2 \mathrm{M}$ were prepared in a special mixing chamber by adding distilled water to $1 \mathrm{M}$ sucrose solution with continuous stirring by a magnetic stirrer. The sucrose solution of decreasing molarity was carefully layered into a centrifuge tube with a polyvinyl tube connected with the bottom of the mixing chamber to a volume of $28.5 \mathrm{ml}$. The test sample, containing $1 \mathrm{mg}$ of endotoxin dissolved in $1 \mathrm{ml} 5 \%$ glucose, was layered over the top through a tuberculin syringe.

Ultracentrifugation was performed in a Spinco model L ultracentrifuge with an SW 25.1 swinging bucket rotor for 17 hours at $25,000 \mathrm{rpm}$ and a running temperature of $+5^{\circ}$ C. After centrifugation the bottom of the centrifuge tube was perforated, and 28 to 30 fractions of 1 $\mathrm{ml}$ were collected in graduated test tubes.

Spectrophotometric analysis. Ultraviolet (UV)-absorption was determined in a Beckman DB spectrophotometer provided with a Photovolt automatic recorder to record scanned UV spectra.

Radioactivity measurements. Radioactivity of $\mathrm{C}^{14}$-labeled samples was determined by suspending samples in thixotropic gel and counting in a Packard Tri-Carb liquid scintillation counter. $\mathrm{Cr}^{\mathrm{sl}}$ radioactivity was measured in a liquid well scintillation counter.4

Gel filtration. Sephadex gel of different porosities was used. Small columns were prepared in disposable plastic or glass syringes with a bed volume of 10 to $70 \mathrm{ml}$. The flow rate was adjusted as desired by using needles of different gauge. Water and saline were used interchangeably as a vehicle for the samples and for elution. Fractions of 1 or $2 \mathrm{ml}$ were collected.

Lethality. Adrenalectomized mice were used to provide a system sensitive enough for assaying the lethality of the minute amounts of endotoxin in fractions of the sucrose gradients. Specific pathogen-free mice (SPF), 5 weighing 15 to $25 \mathrm{~g}$, were challenged 48 hours after adrenalectomy (6). (Conventional mice were unsatisfactory because latent ectromelia infection was activated in them by the surgery.) The SPF mice died between 8 and 48 hours and most between 12 and 24 hours after

4 Nuclear-Chicago Corp., Des Plaines, Ill.

5 Manor Farms, Staatsburg, N. Y. injection of endotoxin. Samples of adjacent fractions from the sucrose gradient were pooled and diluted in normal saline, and $0.25-\mathrm{ml}$ volumes were injected intravenously into 10 to 15 adrenalectomized mice per dilution. The amount of endotoxin injected was determined from its radioactivity. Calculations of the $L D_{50}$ and of the relative potencies with $95 \%$ confidence limits were done by the probit analysis of Finney (11) The data were processed in a computer LGP 30 for which a probit analysis program was written. ${ }^{6}$

Pyrogenicity. The test preparations were injected into the marginal ear vein of carefully conditioned albino rabbits weighing 3 to $5 \mathrm{~kg}$. Rectal temperatures were taken with a Sargent thermistor apparatus hourly for 8-hour periods before and after injection of the samples to be tested and the results expressed in square centimeters of fever according to the method of Keene, Silberman, and Landy (12). The fractions from sucrose gradient were diluted serially tenfold and $0.25-\mathrm{ml}$ portions injected. The dose injected was calculated from the radioactivity of the $\mathrm{C}^{14}$ label. The relative pyrogenic potency of the sucrose gradient fractions as compared to the parent endotoxin was calculated with $95 \%$ confidence limits by the parallel line assay (13). These data were also processed in the computer with a parallel line assay program. ${ }^{6}$

Antibody titration by the hemagglutination procedure. The ability of the test materials to stimulate antibody formation was determined in the rabbits that were used for the pyrogen assay. Seven and 14 days later the titer of serum antibody was determined by hemagglutination of red cells sensitized with alkali-treated endotoxin. The technique for the hemagglutination test has been described elsewhere (14).

Antigen analysis by precipitin reactions in agar. Precipitin reactions in agar were carried out by the method of Ouchterlony (15), as modified by Halbert, Swick, and Soner (16). The antiserum was placed into the center well and the different antigens into the outer wells. The plates were kept for 7 days at $+4^{\circ} \mathrm{C}$.

\section{Results}

\section{Sucrose density gradient analysis of $C^{14}$-labeled E. coli 0:113 endotoxin}

Figure 1 shows the distribution of radioactivity and optical density at $254 \mathrm{~m} \mu$ in a typical sucrose gradient centrifugation of the endotoxin batch E-68- $\mathrm{C}^{14}$. The largest particles were collected in the fractions from the bottom of the gradient, and the smallest were contained in the top fractions. No pellet was formed with any of the

${ }^{6} \mathrm{We}$ are very much indebted to Dr. D. Kodlin, Department of Biostatistics, Graduate School of Public Health, University of Pittsburgh Medical School, and his co-workers who wrote the computer programs and helped us with the evaluation of the results of the bioassays. 


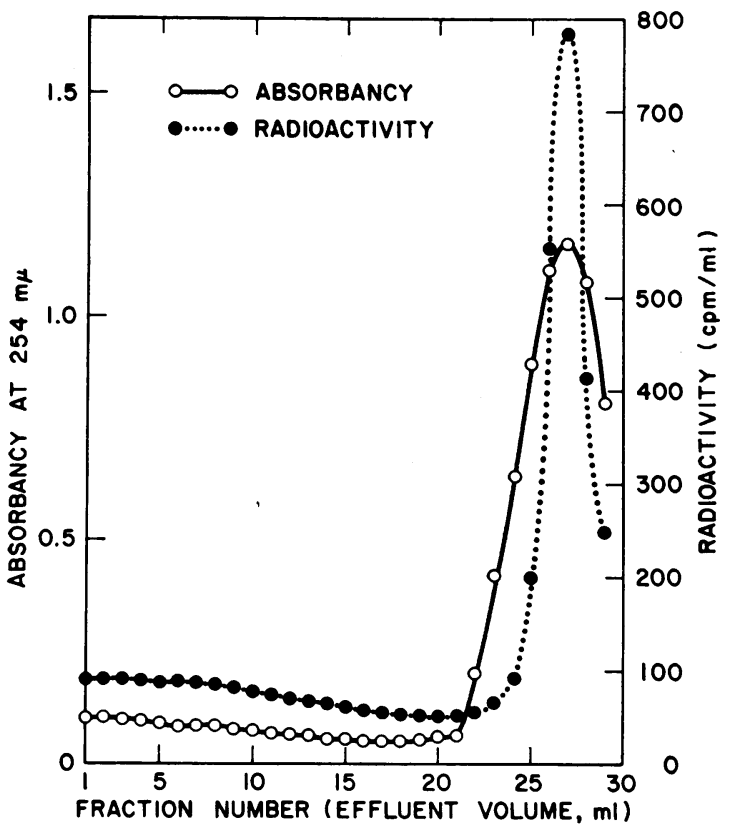

Fig. 1. Distribution OF RADIOACTIVITY AND OPTICAL DENSITY IN SUCROSE DENSITY GRADIENT OF $C^{14}$-LABELED BoIvIN ENDOTOXIN.

radioactive Boivin endotoxins of $E$. coli $\mathrm{O}: 113$ we have tested so far under these conditions of centrifugation. Radioactivity was almost evenly distributed from the bottom of the tube up to

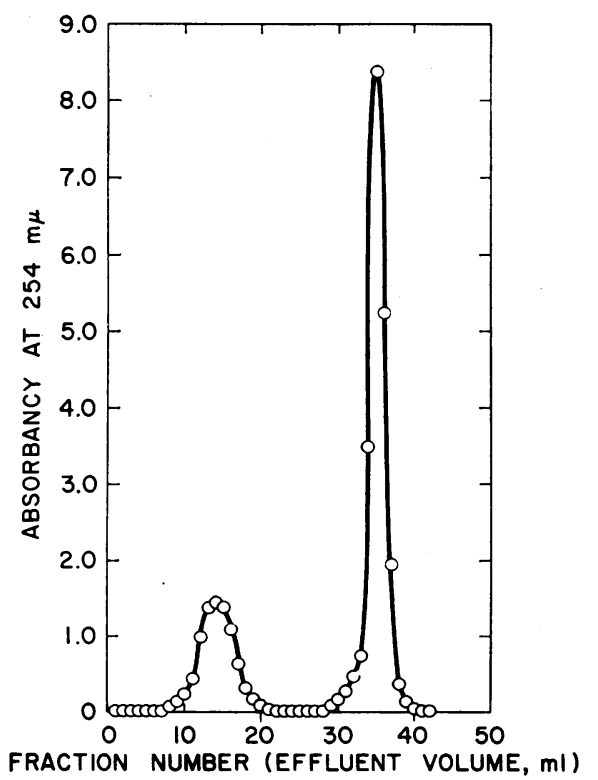

Fig. 2. Gel filtration of E-68 endotoxin on SephaDEX G-25. Bed volume, $50 \mathrm{ml}$; fraction volume, $1 \mathrm{ml}$; flow rate, $20 \mathrm{ml}$ per hour; sample, $3.5 \mathrm{mg}$. about $23 \mathrm{ml}$, a finding indicative of a high degree of polydispersity in the parent endotoxin with variation of particle size over a wide range. In the top fractions, radioactivity and optical density formed a high peak. The UV-absorption spectrum of the peak fraction 27 revealed the presence of a nucleic acid, presumably RNA. The difference in height of the peaks for radioactivity and optical density implies another small molecular compound not absorbing in the UV region. Since approximately $50 \%$ of the total radioactivity, or $0.5 \mathrm{mg}$ of parent endotoxin, was contained in the terminal peak, and assuming an absorbancy

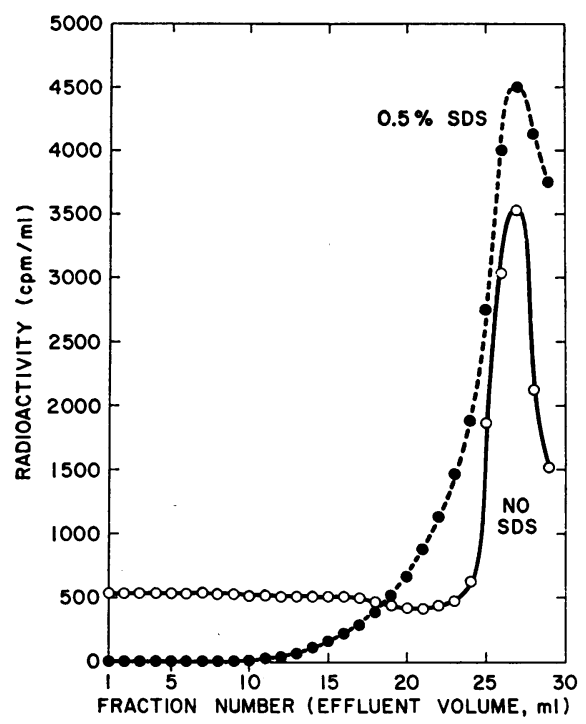

Fig. 3. Distribution of Radioactivity in SUCROSE DENSITY GRADIENT OF $C^{14}$-LABELED ENDOTOXIN BEFORE AND AFTER INCUBATION WITH SODIUM DODECYL SULFATE (SDS).

of about 25 OD U per mg of nucleotide material, the observed peak at $254 \mathrm{~m} \mu$ of about 6 OD U would account for only $50 \%$ of the radioactivity. This nucleic acid contaminant could easily be separated from the parent endotoxin by gel filtration on Sephadex G-25. (Figure 2).

The sucrose density gradient centrifugation of the same batch of endotoxin gave highly reproducible results with virtually identical distribution of radioactivity and optical density. A similar distribution of radioactivity in sucrose gradients was obtained with $\mathrm{C}^{14}$-labeled $E$. coli $\mathrm{O}: 113$ endotoxin (E-69- $\left.\mathrm{C}^{14}\right)$ that possessed no nucleic acid contaminants (Figure 3 ). 
TABLE I

Lethal activity of sucrose density gradient fractions compared to parent endotoxin*

\begin{tabular}{|c|c|c|c|c|}
\hline Pooled fractions & $\mathrm{LD}_{60}$ & $\begin{array}{l}95 \% \text { confidence } \\
\text { limits }\end{array}$ & $\begin{array}{l}\text { Relative } \\
\text { potency }\end{array}$ & $\begin{array}{l}95 \% \text { confidence } \\
\text { limits }\end{array}$ \\
\hline $\begin{array}{c}\text { Parent endotoxin } \\
1-3 \\
4-6 \\
7-10 \\
11-13 \\
14-16 \\
17-20 \\
21-24 \\
25-28\end{array}$ & $\begin{array}{c}\mu g \\
0.152 \\
0.092 \\
0.060 \\
0.056 \\
0.046 \\
0.046 \\
0.075 \\
0.471 \\
\dagger\end{array}$ & $\begin{array}{l}0.116-0.198 \\
0.068-0.123 \\
0.036-0.104 \\
0.036-0.088 \\
0.033-0.065 \\
0.033-0.062 \\
0.053-0.106 \\
0.221-1.00\end{array}$ & $\begin{array}{l}1.00 \\
1.66 \\
2.39 \\
2.73 \\
3.34 \\
3.36 \\
2.04 \\
0.34 \\
t\end{array}$ & $\begin{array}{l}0.94-2.95 \\
1.30-4.40 \\
1.51-4.93 \\
1.51-7.09 \\
1.72-6.53 \\
1.08-3.85 \\
0.17-0.68\end{array}$ \\
\hline
\end{tabular}

* Results calculated by probit analysis (11).

$\dagger$ The toxicity of these fractions was so low that no end point could be obtained in the bioassy. Only one out of ten mice was killed by $2.7 \mu \mathrm{g}$.

Lethality. The $\mathrm{LD}_{50}$ of the parent endotoxin E-68-O :113-C ${ }^{14}$ in normal SPF mice is approximately $300 \mu \mathrm{g}$, and in adrenalectomized mice $0.152 \mu \mathrm{g}$, with $95 \%$ confidence limits of $0.116 \mu \mathrm{g}$ and $0.198 \mu \mathrm{g}$. The sensitivity of the mice to endotoxin is thus increased about 2,000 times after removal of the adrenals.

The distribution of lethality in a sucrose gradient centrifugation of the endotoxin is shown in Table I. The fractions with the highest lethal activity (11 to 16 ) were found in the midportion of the gradient where the increase over the parent endotoxin was approximately threefold. Both the fractions from the bottom and from the top of the gradient were less active. Fractions 1 to 3 were not significantly different from the parent endotoxin but were less active than fractions 11 to 16 . Fractions 4 to 10 and 17 to 20 were still significantly more toxic than the parent endotoxin. Fractions 21 to 28 from the upper part of the gradient were considerably less active than the parent endotoxin.

From the input of $1 \mathrm{mg}$ endotoxin containing about $6,500 \mathrm{LD}_{50}$, we recovered about $5,800 \mathrm{LD}_{50}$ (90\%) in gradient fractions 1 to 24 .

Pyrogenicity. The dose-febrile response curve for the parent endotoxin E-68-O :113-C ${ }^{14}$, with the pyrogenic response expressed as square centimeters of fever, is shown in Figure 4. Each point on the curve represents the mean fever response of four to eight rabbits. From a dose as small as $2.5 \mu \mathrm{g}$ some of the rabbits suffered shock and subsequent drop of temperature far below baseline values, so that they were not used for construction of the curve. The toxic effects after injection of $10 \mu \mathrm{g}$ were probably responsible for the reduced fever response at this dose level.

Single fractions were assayed, and two to four rabbits were used for each dilution. The computer analysis of the fever indexes by the parallel line assay method (13) showed that fractions 1 to 22 were more pyrogenic than the parent endotoxin, with approximate relative potencies between 1 and 14 . Fractions 23 to 28 were less pyrogenic than the parent endotoxin, with approximate relative potencies between 0.25 and 0.007 .

Fever responses higher than $55 \mathrm{~cm}^{2}$ were not considered, and the 28 test preparations showed no evidence of deviation from linearity. Thus the

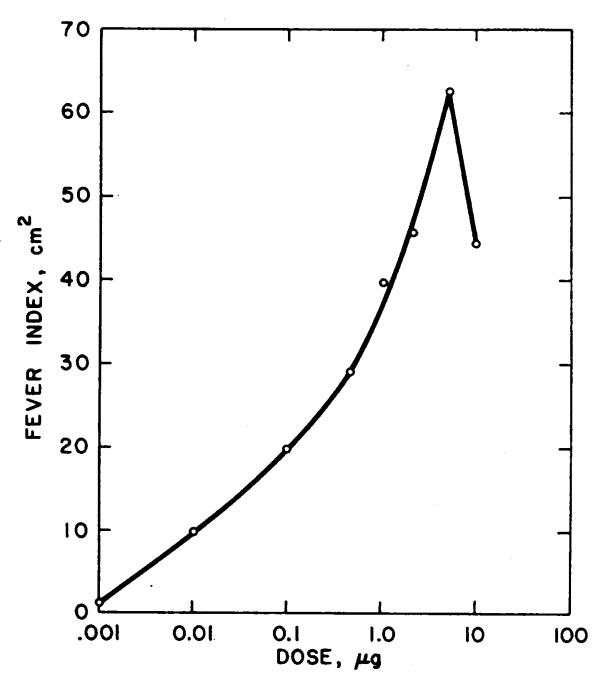

Fig. 4. RELATIONSHIP BETWEEN FEBRILE RESPONSE IN RABBITS AND DOSE OF UNTREATED E. COLI O:113 BoIviN ENDOTOXIN. 
TABLE II

Stimulation of hemagglutinating antibody by a single injection of endotoxin $E-68-C^{14}$, before and after treatment with $0.5 \%$ SDS (sodium dodecyl sulfate)

\begin{tabular}{|c|c|c|c|c|c|c|}
\hline \multirow[b]{2}{*}{ Dose } & \multicolumn{3}{|c|}{ Untreated endotoxin } & \multicolumn{3}{|c|}{ SDS-treated endotoxin } \\
\hline & $\begin{array}{c}\text { No. of } \\
\text { animals }\end{array}$ & $\begin{array}{c}\text { Average } \\
\text { rise in } \\
\text { titer* }\end{array}$ & Range & $\begin{array}{c}\text { No. of } \\
\text { animals }\end{array}$ & $\begin{array}{c}\text { Average } \\
\text { rise in } \\
\text { titer }\end{array}$ & Range \\
\hline \multicolumn{7}{|l|}{ ug } \\
\hline 0.001 & 4 & 1.0 & $0-4$ & 4 & 1.5 & $0-4$ \\
\hline 0.01 & 4 & 11.0 & $4-32$ & 4 & 0.5 & $0-2$ \\
\hline 0.025 & & & & 4 & 1.5 & $0-4$ \\
\hline 0.1 & 8 & 2.5 & $0-4$ & 7 & 1.5 & $0-4$ \\
\hline 0.5 & 4 & 8.5 & $2-16$ & & & \\
\hline 1.0 & 4 & 21.0 & $4-32$ & 4 & 5.0 & $0-16$ \\
\hline 2.5 & 4 & 45.0 & $4-128$ & & & \\
\hline 5.0 & 8 & 32.5 & $4-64$ & 4 & 18.5 & $2-64$ \\
\hline 10.0 & 4 & 80.0 & $16-256$ & 4 & 2.0 & $0-4$ \\
\hline 50.0 & & & & 4 & 1.0 & $0-2$ \\
\hline
\end{tabular}

*A fourfold rise or higher is significant. Rise in titer $=$ final/initial. If no rise occurred, the result is expressed as 0 instead of 1 .

area of fever, in the response range used $(<55$ $\mathrm{cm}^{2}$ ), is linearly related to $\log$ dose.

Five of 28 fractions showed an assay with a deviation from parallelism of response lines (fraction no. $6,8,11,17,21)$, i.e., the slope of the log dose-febrile response curve was significantly different from the slope for the parent endotoxin. Careful analysis of the data, together with an analysis of variance for test preparations that were assayed on a different batch of rabbits at the same dose level, revealed that in some instances significantly different results were obtained with the same preparation. Hence, the observed differences in slope were not due to a fundamental invalidity of the assay system where standard preparation (parent endotoxin) and test (fractions) would not behave like dilutions of one ingredient (13).

Because of these shortcomings of the pyrogen assay, we are not reporting the relative potencies of the 28 fractions and have made no attempt to draw quantitative conclusions. It is safe to say, however, that the fractions 23 to 28 were less active than those from the lower part of the gradient and the parent endotoxin.

A number of fractions from different locations within two other gradients (endotoxin batch $\mathrm{E}$ 69- ${ }^{14}$ ) were also assayed for pyrogenicity. The results were similar to those obtained with the gradient of endotoxin E-68-C ${ }^{14}$.

Titration of antibodies by the hemagglutination procedure. The rise in titer of hemagglutinating antibodies produced by injection of different doses of parent endotoxin is shown in Table II, and that produced by the different fractions of a sucrose gradient is shown in Table III. The stimulus to antibody formation was much greater in fractions from the lower half of the gradient than from the upper 12 fractions. As in the case of pyrogenicity, individual variation within occa-

TABLE III

Stimulation of hemagglutinating antibody by fractions of sucrose gradients

\begin{tabular}{|c|c|c|c|c|c|c|c|c|c|}
\hline \multirow[b]{2}{*}{$\begin{array}{c}\text { Fraction } \\
\text { no. }\end{array}$} & \multicolumn{3}{|c|}{ Dilution $1: 10$} & \multicolumn{3}{|c|}{ Dilution $1: 100$} & \multicolumn{3}{|c|}{ Dilution $1: 1,000$} \\
\hline & $\begin{array}{c}\text { No. } \\
\text { animals }\end{array}$ & $\begin{array}{c}\text { Average } \\
\text { rise in titer* } \\
\text { (final/initial) }\end{array}$ & Range & $\begin{array}{c}\text { No. } \\
\text { animals }\end{array}$ & $\begin{array}{c}\text { Average } \\
\text { rise in titer } \\
\text { (final/initial) }\end{array}$ & Range & $\underset{\text { animals }}{\text { No. }}$ & $\begin{array}{c}\text { Average } \\
\text { rise in titer } \\
\text { (final/initial) }\end{array}$ & Range \\
\hline $\begin{array}{c}1-4 \\
5-8 \\
9-12 \\
13-16 \\
17-20 \\
21-24 \\
25-28\end{array}$ & $\begin{array}{r}8 \\
8 \\
8 \\
8 \\
9 \\
12 \\
30\end{array}$ & $\begin{array}{r}22.00 \\
40.50 \\
16.00 \\
12.25 \\
4.45 \\
3.85 \\
3.75\end{array}$ & $\begin{array}{l}0-64 \\
2-128 \\
2-64 \\
2-64 \\
0-16 \\
0-16 \\
0-16\end{array}$ & $\begin{array}{r}8 \\
12 \\
8 \\
8 \\
8 \\
8 \\
20\end{array}$ & $\begin{array}{l}3.25 \\
9.00 \\
4.00 \\
7.25 \\
2.00 \\
2.5 \\
1.2\end{array}$ & $\begin{array}{l}0-8 \\
2-32 \\
2-8 \\
0-16 \\
0-4 \\
0-8 \\
0-4\end{array}$ & $\begin{array}{r}8 \\
12 \\
8 \\
8 \\
8 \\
8 \\
8\end{array}$ & $\begin{array}{l}0.50 \\
2.20 \\
6.50 \\
4.75 \\
0.250 \\
2.75 \\
0.50\end{array}$ & $\begin{array}{l}0-4 \\
0-4 \\
0-16 \\
0-8 \\
0-2 \\
0-8 \\
0-2\end{array}$ \\
\hline
\end{tabular}

* A fourfold rise or higher is significant. If no rise occurred, the result is expressed as 0 instead of 1. 
WHOLE BOIVIN ENDOTOXIN<smiles>O=S(=O)(O)O</smiles>

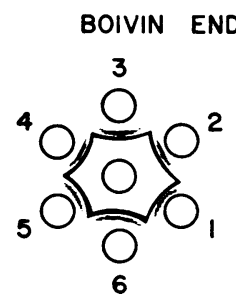

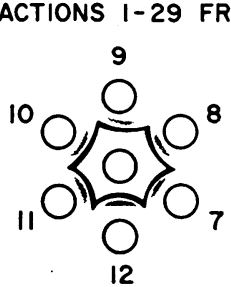

SUCROSE GRADIENT<smiles>[R4]Oc1ccc(O)c(O)c1</smiles>

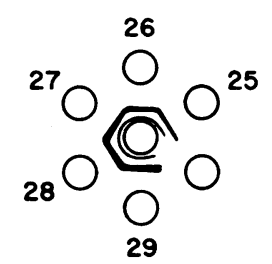

Fig. 5. ANtigen analysis in Agar double diffusion of Parent endoTOXIN AND ENDOTOXIN FRACTIONS OBTAINED BY SUCROSE DENSITY GRADIENT CENTRIFUgation. Antigen in outer wells, serum in center. In the upper plate only one well contains antigen.

sion and batch-to-batch differences made quantitative evaluation of the results impossible.

Antigenic analysis of endotoxin $E-68-O: 113-C^{14}$ in agar double diffusion. A $0.1 \%$ solution of endotoxin E-68-O:113 displayed three precipitation lines against rabbit antiserum prepared by injection of boiled $E$. coli.

Undiluted fractions of the sucrose gradient also produced, as expected, the three precipitation lines of the parent endotoxin (Figure 5). The line of the slow-moving antigenic component was present in fractions 1 to 17 ; in 18 to 23 there was only one line; then the line of the fast-moving antigen close to the center well appeared with increasing intensity.

To get a rough idea of the number of antigenic groups capable of reacting with antiserum, serial twofold dilutions of each fraction were placed in the outer wells and antiserum in the center well of agar diffusion plates. The results are expressed as the reciprocal of the highest dilution to give one clearly visible precipitation line. Figure 6 indicates that the distribution of serological activity is similar to the distribution of radioactivity.
Sucrose density gradient analysis of Criblabeled E. coli endotoxin

Gel filtration on Sephadex showed that nucleic acid contaminants were not labeled.

The behavior of chromate-labeled endotoxin in sucrose gradients was examined with a prepara-

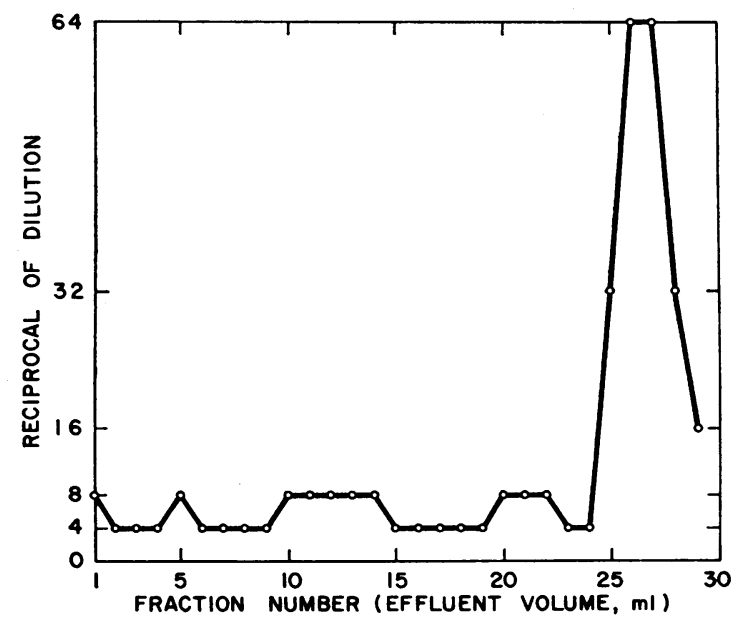

Fig. 6. PRECIPITIN TITERS IN AGar DOUBLE DIFFUSION OF FRACTIONS OBTAINED BY ULTRACENTRIFUGATON OF E. COLI ENDOTOXIN IN SUCROSE GRADIENT. 


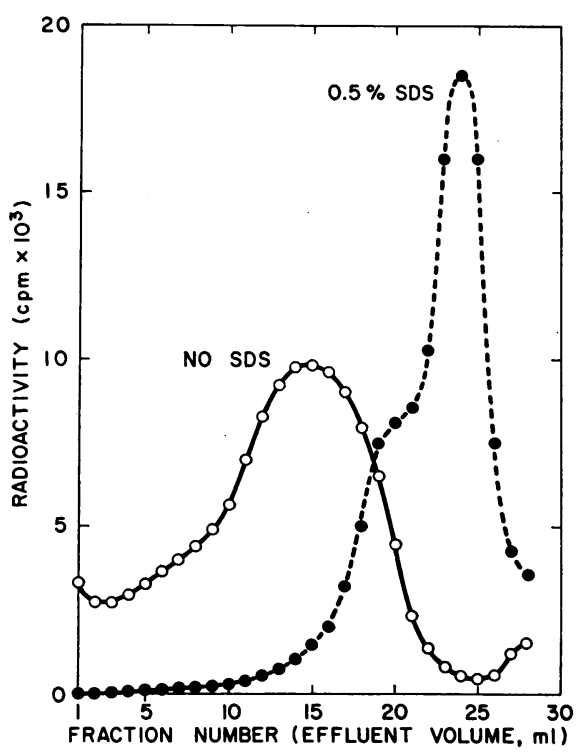

Fig. 7. Distribution OF RAdioactivity IN SUCROSE DENSITY GRADIENT OF CHROMATE-LABELED ENDOTOXIN BEFORE AND AFTER TREATMENT WITH $0.5 \%$ SDS. Note that chromate distribution before SDS treatment closely parallels lethality in Table I.

tion of endotoxin that was originally free of nucleotide contaminants (E. coli O:113-E-67-Cr ${ }^{51}$ ). The labeled endotoxin, with a specific activity of $125,000 \mathrm{cpm}$ per $\mathrm{mg}$, was dissolved in $5 \%$ glucose in a concentration of $1 \mathrm{mg}$ per ml. Figure 7 shows the distribution of radioactivity in a typical gradient of a freshly prepared solution. In contrast to our results with the $\mathrm{C}^{14}$-labeled endotoxin, which showed that $50 \%$ of the radioactivity is associated with the small particles in the fractions at the top, we found that the highest radioactivity from $\mathrm{Cr}^{51}$ appeared in the midportion of the gradient in parallel with the toxic material and that the nontoxic material of low molecular weight was virtually unlabeled. The unlabeled nontoxic antigen in the top fractions was demonstrated by agar double diffusion.

The distribution pattern of the radioactivity of chromate-labeled endotoxin in sucrose gradients was as constant as for $\mathrm{C}^{\mathbf{1 4}}$-labeled endotoxin.

\section{Action of the anionic detergent SDS on endotoxin}

SDS was used in an attempt to dissociate the endotoxin particles of different size into more uniform particles.

A) Sucrose density gradient analysis of endotoxin in the presence of SDS. Solutions of endo- toxin $(0.2 \%)$ in $5 \%$ glucose were mixed with equal volumes of a $1 \%$ solution of SDS in water, shaken vigorously, and allowed to stand for at least 1 hour at room temperature. Longer incubation overnight did not change the result. It was unnecessary to incorporate SDS into the gradient, since the same distribution was obtained with SDS-treated endotoxin whether or not the entire gradient contained $0.5 \%$ SDS.

Figure 3 depicts the distribution in the sucrose gradient of a $\mathrm{C}^{14}$-labeled $E$. coli endotoxin (E$68-\mathrm{C}^{14}$ ) preincubated with $0.5 \%$ SDS. SDS caused a shift of radioactivity to the top of the gradient.

The influence of SDS on the sucrose gradient analysis of a $\mathrm{Cr}^{51}$-labeled endotoxin $(\mathrm{E}-67)$ is shown in Figure 7. The effect of SDS on the sedimentation pattern of endotoxin carrying the chromate label was more pronounced than on the $\mathrm{C}^{14}$-labeled endotoxin. Most of the radioactive material was shifted upward in the gradient with a peak at fraction 24 and a shoulder between fractions 19 and 21. Very little material remained in the lower half of the gradient. The majority of the chromate-labeled components was thus dissociated into two components.

$B$ ) Influence of SDS on agar double diffusion. After incubation with $0.5 \%$ SDS the outermost precipitation line of the untreated endotoxin E-67 disappeared, and the two remaining lines indicated that SDS treatment did not produce a homogeneous antigen. When the endotoxin was separated again from the SDS by precipitation with ethanol, the dissolved precipitate gave the three lines characteristic of the parent (untreated) endotoxin.

Identical agar diffusion patterns were produced with fractions from the sucrose gradient after treatment of either $\mathrm{C}^{14}$ - or chromate-labeled endotoxin with SDS, as shown in Figure 8. No precipitation lines were detectable in fractions 1 to 14 . From fractions 15 to 29 , three different lines developed: 1) an outer, hazy, faint line of a slow-moving antigen was discernible from fractions 20 to 29,2) an inner, well-defined, thin line appeared in fraction 24 and remained visible to fraction 29, and 3) an intermediate line was present from fraction 15 to 29 and shifted toward the center well in the higher fractions, due to an increase in concentration. 
<smiles>COc1ccc(F)c(O)c1</smiles><smiles>[Z6]Oc1cc(O)c(O)cc1O</smiles>

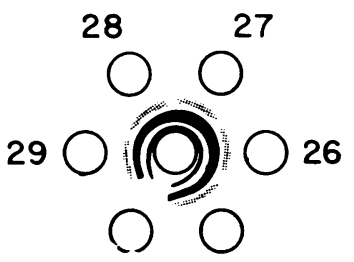

25

Fig. 8. ANTigen ANAlysis in Agar DOUble DIFFusion OF ENDOTOXIN FRACTIONS OBTAINED BY SUCROSE DENSITY GRADIENT CENTRIFUGATION AFTER INCUBATION WITH $0.5 \%$ SDS. Antigens in outer wells, serum in center well. No precipitation lines formed in fractions 1 to 12 .

C) Gel filtration of SDS-treated endotoxin. The dissociation of endotoxin observed under the influence of SDS was next investigated with gel filtration on Sephadex. The columns were equilibrated with a $0.5 \%$ solution of $\mathrm{SDS}$ in $\mathrm{H}_{2} \mathrm{O}$, and the elution was carried out with the same solution. Endotoxin E-67 was dissolved in 0.5\% $\mathrm{SDS}$ in $\mathrm{H}_{2} \mathrm{O}$ in a final concentration of $0.5 \%$. On G-25, G-50, and G-75 the endotoxin was eluted in a single, sharp peak after the void volume, as determined by UV absorption and assay for carbohydrate and protein. On G-100 a shoulder appeared on the right side of the endotoxin peak, which on G-200 was better separated and gave rise to a second peak containing carbohydrate and protein.

D) Bioassays of SDS-treated endotoxin. 1) Pyrogenicity. Intravenous injection of $5 \mathrm{mg}$ of
SDS in $\mathrm{NaCl}$, the highest dose tested, was harmless to rabbits and produced no change in body temperature. E. coli endotoxin E-68-C ${ }^{14}$ was incubated overnight with $0.5 \%$ SDS in saline at concentrations desired for the pyrogen assay. Four to eight animals were injected at each dose level. The pyrogenic response for SDS-treated endotoxin was not significantly different from the untreated endotoxin; the highest response was also found at a dose of $5.0 \mu \mathrm{g}$, and $10.0 \mu \mathrm{g}$ produced a reduced fever respónse.

2) Induction of pyrogen tolerance The results of tolerance studies, illustrated in Figure 9, showed that one injection of $0.5 \mu \mathrm{g}$ SDS-treated endotoxin conferred tolerance 24 hours later to both the SDS-treated endotoxin and the parent endotoxin at the same dose level.

3) Shwartzman phenomenon. The production of the local Shwartzman phenomenon was tested in adult albino rabbits. Twelve rabbits were prepared by an intradermal injection of $0.25 \mathrm{mg}$ endotoxin E-69. Twenty-four hours later, six of these rabbits were challenged by intravenous injection of $0.2 \mathrm{mg}$ endotoxin treated with $0.5 \%$ $\mathrm{SDS}$ in saline. Four of the remaining prepared rabbits received the same dose of untreated endo-

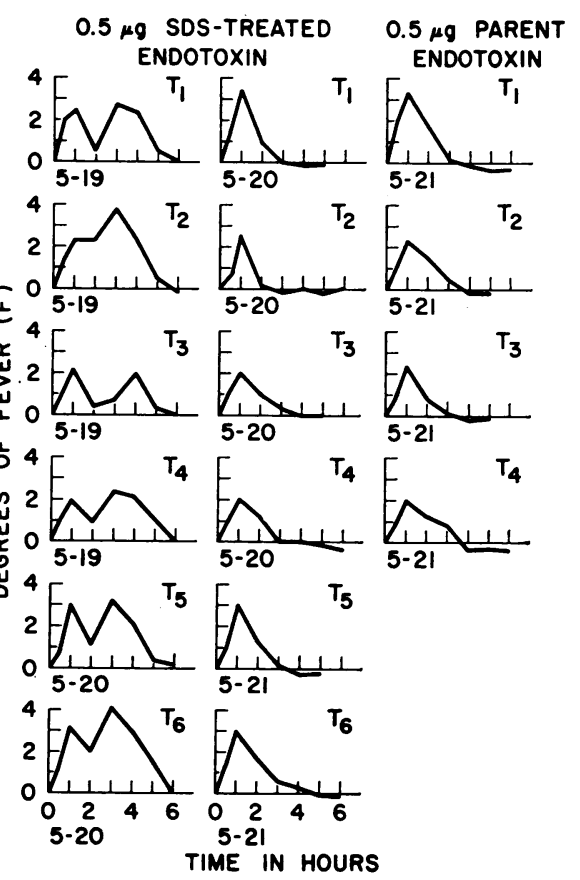

Fig. 9. Production of PYROgen tolerance BY SDSTREATED ENDOTOXIN IN SIX RABBITS $\left(T_{1}\right.$ To $\left.T_{6}\right)$. 
toxin intravenously, and two received $1.25 \mathrm{mg}$ $\mathrm{SDS}$ alone, a dose equal to that given to the first group of rabbits.

Rabbits injected with untreated and those injected with SDS-treated endotoxin developed an identical local Shwartzman reaction, whereas rabbits challenged with SDS alone showed only a delayed inflammatory reaction with no hemorrhage or necrosis at the site of the preparative injection.

SDS-treated endotoxin could not be used for the preparative injection, since SDS causes focal necrosis of the skin upon intradermal injection.

4) Neutropenia. The action on leukocytes of SDS-treated endotoxin was compared to that of untreated endotoxin by injecting $0.5 \mu \mathrm{g}$ or $5 \mu \mathrm{g}$ intravenously into adult albino rabbits. Four animals were used for each dose of SDS-treated or untreated endotoxin. Leukopenia was marked 15 minutes after injection, reached its maximum 1 hour after injection, and was followed by neutrophilia at 4 hours. No significant difference was observed between untreated and SDS-treated endotoxin.

SDS alone in a dose equivalent to the amount given to the animals that received SDS-treated endotoxin caused no appreciable change in the leukocyte count during the time observed.

5) Lethality. The lethality of SDS-treated endotoxin in mice cannot be evaluated because of the high toxicity of SDS upon intravenous or intraperitoneal injection.

The lethal action of SDS-treated endotoxin could be appraised more satisfactorily in rabbits. Six albino rabbits weighing 2.5 to $5 \mathrm{~kg}$ were injected intravenously with each of a series of graded doses of endotoxin that had incubated overnight at room temperature with $0.5 \%$ SDS. All the deaths occurred within 24 hours after injection. The mortality rate for each dose was as follows: $5.0 \mathrm{mg}$ endotoxin, three of six rabbits; $2.5 \mathrm{mg}$ endotoxin, two of six rabbits; 1.25 $\mathrm{mg}$ endotoxin, three of six rabbits; $0.625 \mathrm{mg}$ endotoxin, two of six rabbits; $0.312 \mathrm{mg}$ endotoxin, zero of six rabbits. With $2.5 \mathrm{mg}$ untreated endotoxin, three of six rabbits died.

The lethality of SDS-treated endotoxin in rabbits is similar to that obtained with untreated endotoxin (17). In evaluating the results we have to consider that the lethal action of SDS- treated endotoxin may be due to the presence of undissociated endotoxin as was demonstrated in gel-filtration experiments. The results, therefore, are not conclusive.

6) Antigenicity. The stimulation of hemagglutinating antibody by SDS-treated endotoxin was studied in the same animals that were used for the pyrogen assay. The result are shown in Table II. They indicate that SDS-treated endotoxin is a poor antigen in the rabbit. Whereas a dose of $1.0 \mu \mathrm{g}$ or higher of untreated endotoxin stimulated a fourfold or higher rise in hemagglutinating antibody in 20 of 20 rabbits, only two rabbits of 16 had a higher than fourfold increase in titer, and four rabbits had a fourfold increase with SDS-treated endotoxin.

\section{Discussion}

The finding that toxicity increased with particle size was in keeping with previous impressions that toxicity was a function of size. If this premise were true, it should have been possible to abolish toxicity by depolymerizing the particles into smaller units. The problem was therefore approached by examining simultaneously the effects of SDS on particle size, toxicity, and stability of the chromate label of endotoxin. The results did not support the original premise, for they showed that SDS reduced endotoxin to a small monodisperse particle with a size close to that of the nontoxic fractions of the parent endotoxin, but without a loss of toxic activity or chromate label. ${ }^{7}$ These findings indicated that size is not responsible for toxicity and are reminiscent of those reported by Skarnes and Chedid (19), who isolated from normal mouse serum an alpha globulin fraction that seemed to reduce the molecular size of Salmonella enteritidis endotoxin without producing a loss of toxicity or chromate label. They postulated that reduction in size by a serum component was a preliminary step to detoxification in the blood stream, since normal

7 The effect of SDS varies with the endotoxin. Oroszlan and Mora (18) found a reduction in particle size of Serratia marcescens endotoxin and a striking reduction in its tumor-damaging properties. We obtained a paradoxical effect with a commercial $S$. marcescens endotoxin labeled with chromate; there was a shift of radioactivity towards the bottom of the gradient. This suggested to us that larger aggregates were formed by detergent bridges between the endotoxin particles. 
sera could detoxify the endotoxin only if it had first been dissociated into smaller units by the alpha globulin fraction. This detoxification by serum was accompanied by a loss of the chromate label from endotoxin. The close association of chromate ion with the toxic portion of the Boivin extract was demonstrated not only in the sucrose gradient, but also under a variety of other circumstances in vivo and in vitro $(6,7,19)$. The binding of chromate may thus provide an important clue to the mechanism of toxicity.

The failure of SDS to affect the lethal, pyrogenic, neutropenic, or Shwartzman-inducing properties of endotoxin, or to dislodge the chromate label, indicates that the subunits of the macromolecule possess full toxicity. Although these subunits resemble in size the small nontoxic antigen in the Boivin extract, they are easily recognized as different substances by their toxicity and affinity for the chromate label.

The association of toxicity with large particles in the gradient suggests that the toxic subunits are assembled into large aggregates during synthesis of the cell wall. In addition to the toxic aggregates, it would seem that nontoxic aggregates of variable size are present in the Boivin antigenic complex and reduce toxicity per unit weight on both sides of the peak defined by lethality and chromate labeling. The failure of SDS-treated endotoxin to stimulate formation of hemagglutinating antibody suggests that toxicity may be dissociated from immunogenicity, but not from the ability to induce tolerance. Although this dissociation could represent the destruction of a nontoxic contaminating antigen, it might also result from the degradation of a toxic antigen into subunits too small for antibody stimulation.

To solve this problem and others raised by the present study, we are pursuing the separation of the toxic from the nontoxic fraction of the endotoxin complex and attempting to clarify the nature of the reaction between chromate and endotoxin.

\section{Summary}

The relationship between particle size and biological activity of Escherichia coli $\mathrm{O}: 113$ endotoxin (Boivin) labeled with $\mathrm{C}^{14}$ or $\mathrm{Cr}^{51}$ was studied within a density gradient containing sucrose in concentrations ranging from 10 to $34 \%$. Approximately one-half of the Boivin extract collected near the top of the gradient as a relatively nontoxic substance capable of precipitating antiserum in agar but showing little if any capacity to stimulate antibody formation. The remainder of the endotoxin complex was uniformly distributed throughout the gradient with peak toxicity in the midportion of the gradient. Radioactivity from chromate-labeled endotoxin seemed intimately associated with toxicity, in contrast to that from $\mathrm{C}^{14}$, which was uniformly distributed throughout the endotoxin complex and produced a high peak at the top of the gradient. Dodecyl sulfate reduced the endotoxin into small monodisperse particles that appeared near the top of the gradient with a sharp reduction in ability to stimulate antibody formation but no demonstrable loss of toxicity or chromate label. The results indicate that toxicity is not a function of particle size, despite an apparent association between size and toxicity in endotoxin prepared by the Boivin technique. This association of toxicity with large particles suggests that the toxic subunits are assembled into large aggregates during synthesis of the bacterial cell wall.

\section{References}

1. Westphal, O., O. Luderitz, and F. Bister. Utber die Extraction von Bacterien mit Phenol/Wasser. Z. Naturforsch. [B] 1952, 7b, 148.

2. Fukushi, L., R. L. Anacker, W. T. Haskins, M. Landy, K. C. Milner, and E. Ribi. Extraction and purification of endotoxin from enterobacteriaceae: a comparison of selected methods and sources. J. Bact. 1964, 87, 391.

3. Ribi, E., W. T. Haskins, K. C. Milner, R. L. Anacker, D. B. Ritter, G. Goods, R. J. Trapani, and M. Landy. Physicochemical changes in endotoxin associated with loss of biological potency. J. Bact. 1962, 84, 803.

4. Haskins, W. T., M. Landy, K. C. Milner, and E. Ribi. Biological properties of parent endotoxin and lipoid fractions, with a kinetic study of acid-hydrolyzed endotoxin. J. exp. Med. 1961, 114, 665.

5. Nakano, M. Mutants of Salmonella with unusually low toxicity for mice. Nature (Lond.) 1962, 196, 1118.

6. Chedid, L., R. C. Skarnes, and M. Parant. Characteristics of a $\mathrm{Cr}^{51}$-labelled endotoxin and its identification in plasma and urine after parenteral administration. J. exp. Med. 1963, 117, 556. 
7. Chedid, L., M. Parant, F. Boyer, and R. C. Skarnes. Nonspecific Host Responses in Tolerance to the Lethal Effect of Endotoxin, Symposium on Endotoxins. New Brunswick, Rutgers University Press, 1964, p. 500.

8. Schramm, G., O. Westphal, and O. Luderitz. Über bakterielle Reizstoffe. III. Mitteilung Physikalisch-chemisches Verhalten eines hochgereinigten Coli-Pyrogens. Z. Naturforsch. [B] 1952, 7b, 594.

9. Noll, H., and A. I. Braude. Preparation and biological properties of a chemically modified Escherichia coli endotoxin of high immunogenic potency and low toxicity. J. clin. Invest. 1961, 40, 1935.

10. Braude, A. I., F. J. Carey, D. Sutherland, and M. Zalesky. Studies with radioactive endotoxin. I. The use of $\mathrm{Cr}^{51}$ to label endotoxin of Escherichia coli. J. clin. Invest. 1955, 34, 850.

11. Finney, D. J. Probit Analysis, 2nd ed. Cambridge, University Press, 1952.

12. Keene, W. R., H. R. Silberman, and M. Landy. Observations on the pyrogenic response and its application to the bioassay of endotoxin. J. clin. Invest. 1961, 40, 295.
13. Finney, D. J. Statistical Methods in Biological Assays. London, Charles Griffin, 1952.

14. Braude, A. I., J. L. Jones, and H. Douglas. The behavior of Escherichia coli endotoxin (somatic antigen) during infectious arthritis. J. Immunol. 1963, 90, 297.

15. Ouchterlony, O. In vitro method for testing toxin producing capacity of diphtheria bacteria. Acta path. microbiol. scand. 1948, 25, 186.

16. Halbert, S. P., L. Swick, and C. Soner. The use of precipitin analysis in agar for the study of human streptococcal infections. II. Ouchterlony and Oakley techniques. J. exp. Med. 1955, 101, 557.

17. Gilbert, V. E., and A. I. Braude. Reduction of serum complement after injection of endotoxin. J. exp. Med. 1962, 116, 477.

18. Oroszlan, S. I., and P. T. Mora. Dissociation and reconstitution of an endotoxin. Biochem. biophys. Res. Commun. 1963, 12, 345.

19. Skarnes, R. C., and L. C. Chedid. Biologic Degradation and Inactivation of Endotoxin (ChromateLabelled), Symposium on Endotoxins. New Brunswick, Rutgers University Press, 1964, p. 575. 